\title{
PREVALENCE OF FUNCTIONAL DYSPEPSIA IN A RURAL MEDICAL COLLEGE HOSPITAL
}

Venkatarathnamma P. N¹, Anil Kumar Mannava², Ujjawal Kumar³, Chethan", Reethesh R. P5

HOW TO CITE THIS ARTICLE:

Venkatarathnamma P. N, Anil Kumar Mannava, Ujjawal Kumar, Chethan, Reethesh R. P. "Prevalence of Functional Dyspepsia in a Rural Medical College Hospital". Journal of Evolution of Medical and Dental Sciences 2014; Vol. 3, Issue 08, February 24; Page: 1934-1939, DOI: 10.14260/jemds/2014/2083

ABSTRACT: BACKGROUND: The term "dyspepsia" is derived from the Greek language and it literally means "bad digestion." 1 Dyspepsia is a common complaint among individuals seeking medical care as well as in general population. Rome III a recent consensus, has defined dyspepsia as the presence of symptoms considered by the physician to originate from the gastroduodenal region and only four symptoms (bothersome postprandial fullness, early satiation, epigastric pain, and epigastric burning) are now considered to be specific for a gastroduodenal origin, although many other symptoms are acknowledged to coexist with dyspepsia. Patients having chronic dyspeptic symptoms for the past 3 months with onset at least 6 months before diagnosis in absence of structural abnormality on upper GI endoscopy and metabolic or systemic causes explaining the symptoms are classified as Functional Dyspepsia (FD) ${ }^{2}$. Prevalence of dyspepsia is about 20-30\% worldwide 3 . Functional dyspepsia (FD) or essential dyspepsia is characterized by upper abdominal pain without the presence of an ulcer 4 . People with functional dyspepsia have a significantly reduced quality of life when compared to the general population 5 .

KEYWORDS: Dyspepsia, Functional Dyspepsia, Endoscopy.

Magnitude of Problems of Functional Dyspepsia (FD) in India: From the limited data available, it was found that 7.6 to $49 \%$ of Indian population report dyspeptic symptoms.6, 7,8

Age and gender: Majority of population-based studies do not show any gender difference in dyspepsia prevalence and few studies found that the prevalence is more in old age population. ${ }^{6}$

Predisposing factors: The role of Helicobacter Pylori (H pylori) in FD is still unclear. Cause and effect relationship has not yet been established beyond doubt. Seroprevalence of H. pylori is high in developing countries such as India. 80\% of Indian adults have antibodies against H. pylori in their sera. ${ }^{9}$ However, even subjects without dyspeptic symptoms are frequently positive to H. pylori antibody. ${ }^{10}$ Many randomized controls trials evaluated effect of $\mathrm{H}$. pylori eradication on symptoms of FD. ${ }^{11-18}$ Most studies, however, showed conflicting results. Data is lacking to prove whether Giardia lamblia infection or salmonella infection may lead to the development of FD.

Dietary Factors: Rice-based diet, popular among many Asian population may be better tolerated than Western wheat-based diet by many patients with functional bowel disorders. ${ }^{19}$

Smoking, alcohol and Non-steroidal anti-inflammatory drugs (NSAIDs): Association of regular smoking, alcohol intake and dyspepsia has not been consistent. Two population based studies have revealed a relationship of dyspepsia and NSAIDs. In a British study of 4982 adults, NSAID usage was 
identified as an independent risk factor for UD and thought to be responsible solely for $4 \%$ of dyspepsia in the community ${ }^{20}$. In a study of American adults from a single institution, regular usage of NSAIDs and Aspirin, bought over the counter, were strongly associated with UD than in controls without dyspepsia. ${ }^{21}$

Socio-economic associations: In majority of population-based studies prevalence of dyspepsia have not been found to be linked with social class. However studies examining details of socio-economic status were able to elicit associations with dyspepsia. In a British study it was found that people from lower socioeconomic classes were more affected with FD. ${ }^{20}$

Psychological Associations: The most common psychiatric co morbidities in patients with functional dyspepsia are anxiety disorders, depressive disorders, somatoform disorders, and a recent or remote history of physical or sexual abuse. Talley et al had reported in an American adult population that sexual, emotional and verbal abuse either in childhood or adulthood were significantly associated with dyspepsia ${ }^{22}$. A population-based study from Hong Kong revealed that anxiety was associated medical consultation and sick leave among patients with dyspepsia and IBS and degree of anxiety was an independent factor associated with health care seeking behavior in dyspeptic patients. ${ }^{23}$

AIM: To study the prevalence of functional dyspepsia, its association with various factors and outcome to treatment in a rural area in south India.

\section{MATERIALS AND METHODS:}

Inclusion criteria:

Patients with chronic or recurrent abdominal pain or discomfort centered in the upper abdomen lasting at least 3 months and at least $25 \%$ of the time were included in the study.

\section{Exclusion criteria:}

1) Age less than 18yrs.

2) Known cases of peptic ulcer.

3) Patients on medications known to cause dyspepsia and other gastro intestinal side effects.

4) Systemic illness (coronary artery disease, liver disease, chronic obstructive airway disease, malignancy, thyroid disease).

This is a prospective study done over a period of 12 months from 1-1-2011 to 31-12-2011, wherein 795cases of abdominal discomfort were evaluated.

Clinical manifestations: include chronic or recurrent abdominal pain or discomfort centered in the upper abdomen lasting at least 3 months and at least 25\% of the time, belching, diarrhea, flatulence, drug history, stresses, Diabetes Mellitus, cardiac disease, thyroid disorder, family and personal history recorded. 
Management included: routine laboratory, ultrasound examination, serology for H-pylori, ECG and upper gastrointestinal endoscopy was done in all. Colonoscopy and stool test was done in 3 cases.

Treatment included lifestyle modifications like eating on time, avoiding heavy/ fatty meals, spices, caffeine, alcohol, NSAIDs, tobacco and light exercise for sedentary lifestyle, antacids, H2RA, Proton pump inhibitors, Sucralfate, Prokinetic agents( mosapride and domperidone), antiflatulent agents, probiotics, H. pylori eradication therapy, low-dose tricyclic antidepressant drugs and invariably psychotherapy.

The data was analyzed for age, sex, treatment given and outcome.

RESULTS: Patients with functional dyspepsia ranged from age of 18 yrs. to 70yrs with Male to female ratio of $1.4: 1$.

Out of total 795 cases, 115 cases (14.5\%) of functional dyspepsia were found. Upper gastrointestinal endoscopy was normal in these 115 cases.

Age distribution: The following is the distribution of patients according to age. Number of patients between 18-40 years was 64 (55.65\%), between 41-50 years 23 cases (20\%) and those above 51 years 28 cases $(24.34 \%)$.

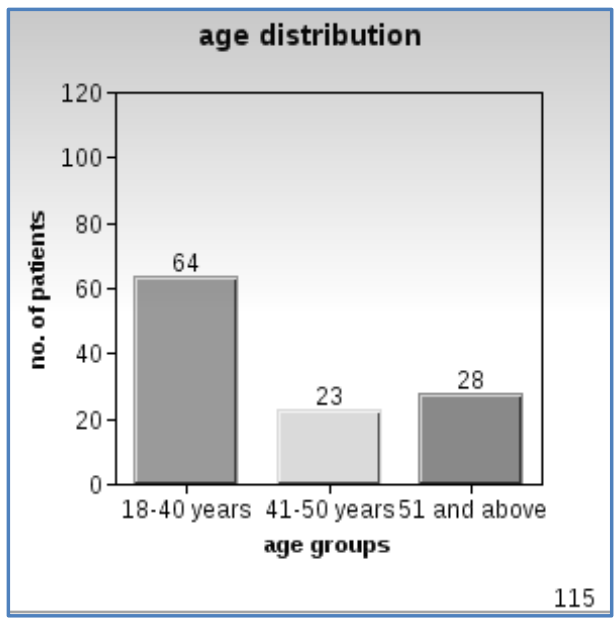

All patients were managed on outpatient basis. Nausea, diarrhea and abdominal discomfort were found in 3 patients (IBS overlap with dyspepsia).

Majority of our patients were from rural residence with 60cases (52\%), and Consumption of Spicy diet was seen in 40 cases (34.7\%).

46 patients of the functional dyspepsia group are smokers, and $46(40 \%)$ patients consumed alcohol.

8 patients were already receiving anti H. Pylori treatment before presenting to our OPD, whose endoscopy findings were normal and on continued treatment with the same drugs the patients' responses were not satisfactory. 23(20\%) patients were found to be having H. Pylori and received antibiotics.

80 patients are literates (69.5\%), and $98(85.2 \%)$ patients are found to have various stresses (At studies, marital, workplace, financial, familial). 
DISCUSSION: Out of 795 cases of abdominal discomfort in this study, functional dyspepsia constituted about $14.5 \%$ with multifactorial predisposition. A study from India done by Shaw SS et.al., reported prevalence of dyspepsia to be $30.4 \% .{ }^{6}$ In another multi-centric study from India done by Goshal UC et.al., primarily targeted to study epidemiology and clinical profile of irritable bowel syndrome (IBS, another functional bowel disorder that may overlap with FD), found frequency of dyspeptic symptoms to be as high as $49 \%$ in community. ${ }^{7}$ In a study from Chandigarh, done by Singh V et.al., of 2048 individuals, 155 (7.5\%) had dyspepsia (defined as intermittent or persistent pain, nausea or discomfort referable to the upper alimentary tract that has been present for 1 month or more and was unrelated to exertion). ${ }^{8}$

In a study from urban Mumbai, done by Shaw S S et.al, it was found that dyspepsia was more prevalent in adults $>40$ years $^{6}$. But in our study, the prevalence is found to be common in young patients of 18-40years age group.

Study from Mumbai, India have shown that vegetarians or non-vegetarian diet have no effect on dyspeptic symptoms, and spicy, fried or food prepared outside the home contributed insignificantly to worsening of symptoms. ${ }^{6}$ In our study the consumption of spicy diet is found in $34.7 \%$ of the patients.

In our study $40 \%$ of the patients were smokers and $40 \%$ consumed alcohol. Two studies from India 6 and New Zealand ${ }^{24}$ have showed definite associations between alcohol and UD.

This study shows Functional dyspepsia is not uncommon disorder in an otherwise healthy population; there was no organic cause and no mortality.

Over 3-4 months 98 patients (85.2\%) responded to therapy and others were lost for followup.

There was no disturbance with working in all patients in spite of chronic suffering.

CONCLUSION: Functional dyspepsia is a diagnosis of exclusion, management of which is a clinical challenge. In our study FD was found in younger population group with almost equal gender disturbance, and is mostly associated with various stressors like consuming spicy food, smoking, and alcoholism, and other various stressors (At studies, marital, workplace, financial, familial).

\section{REFERENCES:}

1. Minocha A, Wigington WC, Johnson WD. Detailed characterization of epidemiology of uninvestigated dyspepsia and its impact on quality of life among African Americans as compared to Caucasians. Am J Gastroenterol. 2006; 101:336-42.

2. Tack J, Talley NJ, Camilleri M, et al. Functional gastroduodenal disorders. Gastroenterology. 2006; 130:1466-1479.

3. Grainger SL, Klass HJ, Rake MO. Prevalence of dyspepsia: the epidemiology of overlapping symptoms. Postgrad Med J. 1994; 70:154-161.

4. Valle JD. Peptic ulcer disease and related disorders. In: Longo, Fauci, Kasper, Hauser, Jameson, Loscalzo, editors. Harrison's principles of internal medicine.18 ${ }^{\text {th }}$ ed. McGraw-Hill Companies Inc, USA. 2012, p. 2438-2460.

5. Chang L. Epidemiology and quality of life in functional gastrointestinal disorders. Aliment Pharmacol Ther. 2004; 7:31-39. 
6. Shah SS, Bhatia SJ, Mistry FP. Epidemiology of dyspepsia in the general population in Mumbai. Indian J Gastroenterol. 2001; 20:103-106.

7. Ghoshal UC, Abraham P, Bhatt C, et al. Epidemiological and clinical profile of irritable bowel syndrome in India: report of the Indian Society of Gastroenterology Task Force. Indian J Gastroenterol. 2008; 27:22-28.

8. Singh V, Trikha B, Nain CK, Singh K, Vaiphei K. Epidemiology of helicobacter pylori and peptic ulcer in India. J Gastroenterol Hepatol. 2002; 17:659-6.

9. Ghoshal UC, Chaturvedi R, Correa P. The enigma of helicobacter pylori infection and gastric cancer. Indian J Gastroenterol. 2010; 29:95-100.

10. Ghoshal UC, Tiwari S, Dhingra S, Pandey R, Ghoshal U, Tripathi S, Singh H, Gupta VK, Nagpal AK, Naik S, Ayyagari A. Frequency of helicobacter pylori and caga antibody in patients with gastric neoplasms and controls: the Indian enigma. Dig Dis Sci. 2008; 53:1215-22.

11. Mahadeva S, Chia YC, Vinothini A, Mohazmi M, Goh KL. Cost effectiveness of and satisfaction with a Helicobacter pylori "test and treat" strategy compared with prompt endoscopy in young Asians with dyspepsia. Gut. 2008; 57:1214-1220.

12. Naffeza MI, Isa MR, Kudva MV, et al. Helicobacter pylori related functional dyspepsia in a defined Malaysian population. Malaysian Journal of Medical Sciences. 2000; 7:22-26.

13. Miwa H, HIRA S, Nagahara A, et al. Cure of Helicobacter pylori infection does not improve symptoms in non-ulcer dyspepsia patients - double-blind placebo-controlled study. Aliment Pharmacol Ther. 2000; 14:317-324.

14. Su YC, Wang WM, Wang SY, et al. The association between helicobacter pylori infection and functional dyspepsia in patients with irritable bowel syndrome. Am J Gastroenterol.2000; 95:1900-1905.

15. Kaur G, Naing NN. Prevalence and ethnic distribution of helicobacter pylori among endoscopic patients in north eastern peninsular Malaysia. Malaysian Journal of Medical Sciences.2003; 10:66-70.

16. Tan HJ, Rizal AM. Role of helicobacter pylori virulence factor and genotypes in non-ulcer dyspepsia. J Gastroenterol Hepatol. 2003; 21:110-115.

17. Kim JE, Rhee PL, Kim Y-H, et al. Association of Helicobacter pylori infection with gastric hypersensitivity in functional dyspepsia. Kor J Gastroenterol. 1999; 34.

18. Hsu PI, Lai KH, Lo GH, Tseng HH, et al. Risk factors for ulcer development in patients with non-ulcer dyspepsia: a prospective two year follow up study of 209 patients. Gut. 2002; 51:15-20.

19. Wahnschaffe U, Schulzke JD, Zeitz M, Ullrich R. Predictors of clinical response to gluten- free diet in patients diagnosed with diarrhea predominant irritable bowel syndrome. Clin Gastroenterol Hepatol. 2007; 5:844-850.

20. Moayyedi P, Forman D, Braunholtz D, Feltbower R, Crocombe W, Liptrott M, Axon A. The proportion of upper gastrointestinal symptoms in the community associated with Helicobacter pylori, lifestyle factors, and nonsteroidal anti-inflammatory drugs. Leeds HELP Study Group. Am J Gastroenterol. 2000; 95:1448-1455.

21. Shaib Y, El-Serag HB. The prevalence and risk factors of functional dyspepsia in a multiethnic population in the United States. Am J Gastroenterol. 2004; 99:2210-2216. 
22. Talley NJ, Fett SL, Zinsmeister AR, Melton LJ. Gastrointestinal tract symptoms and selfreported abuse: a population based study. Gastroenterology. 1994; 107:1040-49.

23. Hu WH, Wong WM, Lam CL, et al. Anxiety but not depression determines health care-seeking behaviour in Chinese patients with dyspepsia and irritable bowel syndrome: a populationbased study. Aliment Pharmacol Ther. 2002; 16:2081-2088.

24. Haque M, Wyeth JW, Stace NH, Talley NJ, Green R. Prevalence, severity and associated features of gastro-oesophageal reflux and dyspepsia: a population-based study. NZ Med J. 2000; 113:178-181.

\section{AUTHORS:}

1. Venkatarathnamma P. N.

2. Anil Kumar Mannava

3. Ujjawal Kumar

4. Chethan

5. Reethesh R. P.

\section{PARTICULARS OF CONTRIBUTORS:}

1. Professor, Department of General Medicine, Sri Devaraj Urs Medical College, Tamaka, Kolar.

2. Resident, Department of General Medicine, Sri Devaraj Urs Medical College, Tamaka, Kolar.

3. Resident, Department of General Medicine, Sri Devaraj Urs Medical College, Tamaka, Kolar.

4. Assistant Professor, Department of General Medicine, Sri Devaraj Urs Medical College, Tamaka, Kolar.
5. Assistant Professor, Department of General Medicine, Sri Devaraj Urs Medical College, Tamaka, Kolar.

\section{NAME ADDRESS EMAIL ID OF THE CORRESPONDING AUTHOR:}

Dr. Venkatarathnamma P. N, Professor, Department of General Medicine, Sri Devaraj Urs Medical College, Tamaka, Kolar.

E-mail: drpnvr@rediffmail.com

Date of Submission: 01/02/2014.

Date of Peer Review: 03/02/2014.

Date of Acceptance: 13/02/2014.

Date of Publishing: 20/02/2014. 